\title{
Histological study of the effects of cypermethrin on liver and kidney tissues of mice model.
}

\author{
M.A.A.Mamun ${ }^{1}$, I.J.Illa ${ }^{2}$, K.M.F.Haque ${ }^{1}$ and Z.Ferdousi* \\ ${ }^{1}$ (Protein Science Lab, Department of Genetic Engineering and Biotechnology, University of Rajshahi, Rajshahi \\ 6205, Bangladesh) \\ ${ }^{2}$ (Entomology lab, Department of Genetic Engineering and Biotechnology, University of Rajshahi, Rajshahi \\ 6205, Bangladesh)
}

\begin{abstract}
Cypermethrin is a synthetic pyrethroid pesticide widely used to protect crop against pest and insect, resulting human health and their related environment are under great risk due to undesirable toxicity. The present study was carried out to evaluate extinct of damage caused by subcutaneous introduction of cypermethrin on liver and kidney tissue of mice model. Forty switch albino mice were dispense mainly into two groups as control and treatment group. The animals of three treatment groups (each group contain ten animal) were provided ordinary poultry food containing cypermethrin at dose level of $5,7.5 \& 10 \mathrm{ml} / \mathrm{kg}$ body weight respectively for different period based on the number of treated group. After ending treatment period, the animals were sacrificed for histological study and visualized under light microscope. Result were demonstrated enlargement in the sinusoidal space, vacuole formations in hepatocytes, leucocytic infiltrations, congestion of blood vessels with hemorrhage in hepatic tissue and shrinkage of glomeruli, necrosis of renal tubules, deleted blood vassal and severe congestion of renal glomerulus along with hemorrhage in renal tissues compared with the regular organization of their control. Therefore, we strongly recommend for the ban of cypermethrin and searching out nontoxic pesticide for agricultural use.
\end{abstract}

Keyword: Cypermethrin, histology, kidney, liver and Mus musculus.

\section{Introduction}

Cypermethrin[Cyano-(3-phenoxyphenyl)methyl]3-(2,2-dichloroethenyl)-2,2-dimethylcyclopropane-1carboxylate] is a viscous semi solid,yellowish brown colored andodorlesschemicalwith Molecular formula: $\mathrm{C}_{22} \mathrm{H}_{19} \mathrm{Cl}_{2} \mathrm{NO}_{3}$. It is a synthetic pyrethroid pesticide having three chiral centers, giving a racemic mixture of all eight possible chiral isomecomprising four diasterioisomeric pairs. Its structure is based on pyrethrum (a natural insecticide produced from chrysanthemum flowers) having higher biological activity and stability than its natural model [1]. It is light stable and available as an emulsifiable concentrate or wettable powder. Cypermethrin enter into our environment through its application as an agricultural pesticide, during its manufacture, transportation and storage. Cypermethrin is primarily absorbed from gastrointestinal tract and may also be absorbed by inhalation of spray mist and only simply through the intact skin. Due to its lipophilic nature, cypermethrin has been found to accumulate in body fat, skin, liver, kidneys, adrenal glands, ovaries and brain [2]. The ingredient of this chemical have been identified in human milk from malarial endemic areas in South Africa [3].This type II pyrethroid has been widely used to control ectoparaside including moth pests, cockroaches, fleas, and termites of cotton, fruit and vegetable [4].After manufacturing in 1974 by American companyit is approved for using on a broad range of crops including apple, barley, broccoli, calibers, brussels sprout, cabbage, cauliflower, field bean, fodder beet, grassland, kale, mangle, oats, oilseed rape, pear, potato, red beet, rye, sugar beet, triticale,vining pea and wheat. This pesticide often synergistically used with many other pesticides to increase potency and persistency in the environment. Cypermethrinare the most effective means of pest eradication, but their use has arrived at frightening rate due to a number of undesirable effects on non-target organisms including human beings [5]. Basically it is neurotoxin acts by quickly affecting the insect's central nervous system [6]. Cypermethrin worked by rising the open time of sodium channels resulting prolonged membrane depolarization, releasing enhance level of neurotransmitter (results in multiple nerve impulses instead of the usual single one) and repetitive neuronal activity; ultimately leading to depletion of the neurotransmitter [7, 8]. It slowdowns the activity of amino butyric acid receptor, following excitability and convulsions [9]. Additionally, it also blocks voltage-sensitive chloride channels [10] and inhibit monoamine oxidase, an enzyme that breaks down neurotransmitters [11]. As a result, a wide range of disorder related to the use of cypermethrin has been reported on insect, animal, birds, and fishes even human. Acute toxicity including abnormal facial sensations, dizziness, headache, nausea, anorexia and fatigue, vomiting and increased stomach secretion irritant to skin and eye persistently muscular twitching, comata and convulsive attacks. It affects various systems in our body including hematological, biochemical, dermatological, muscular, urinary, central nervous system and digestive system [12]. Though carcinogenic data related to the uses of cypermethrin was not enough available ${ }^{1}$ 
but showing genotoxicity in mouse spleen and bone marrow [13]. Long-term exposure has been reported to induce dopaminergic neurodegeneration during adulthood in rats [14]. Several studies demonstrated that cypermethrin provoke a range of physiological, biochemical, toxicological, and histological changes in different experimental animals $[15,16]$. Due to its extensive utilization as pesticide in agricultural and other sector resulting serious environmental hazard along with deleteriously effect on non-target organism, the technologist of some countries are searching to apply biological and other nonpolluting ways for fighting against pest. In Bangladesh, the activity of Pesticide Incident Monitoring System (PIMS) is not sufficient to manage of selling contaminated food stuffs with ingredient of pesticide and general public unfortunately consuming and subjected to severe health risk. Therefore, there is an utmost need to evaluate the degree of injury caused by cypermethrin intoxication continuously and find out safety dose of cypermethrinthat successfully manage pest, on other side is risk free to human beings and other non-target organism besides .

\subsection{Experimental Animals:}

\section{Materials and Methods}

Forty matured female albino mice weighing around 25-30gm (80-90 days old) were purchased from the Department of Pharmacy of the University of Jahangirnagar, Dhaka, Bangladesh. All mice were handled in accordance with the typical guide for care and use of laboratory animals (under the license of Institutional animal, medical ethics, bio-safety and bio-security committee (IAMEBBC) for experimentations on animal, human, microbes and living natural sources . No. 33/320/IAMEBBC/IBSC).

\subsection{Chemicals:}

Cypermethrin(57\% EC) was purchased from local super market of Rajshahi by the trade name of “cyperin"produced by SQUARE Pharmaceuticals Ltd. The concentration cypermethrin of was calculated from the percentage of active ingredient of commercial formulation of cypermethrin.

\subsection{Experimental design:}

Forty matured female switch albino mice were randomly distributed into two groups, as control and treatment.

\subsubsection{Control group:}

A total of ten mice were feed with ordinary poultry food (6 gm/mouse) and ample water without any ingredient of cypermethrin.

\subsubsection{Treatment groups:}

There were three treatment groups containing ten animals in each group.

- Group 1: Experimental animals were subcutaneously introduced of cypermethrin at a dose level of 5 $\mathrm{mg} / \mathrm{kg}$ body weight for a period of 7 days, 14 days, 21 days and 28 days.

- Group 2: Experimental animals were subcutaneously introduced of cypermethrin at a dose level of $0.7 .5 \mathrm{mg} / \mathrm{kg}$ body weight for a period of 7 days, 14 days, and 21 days.

- Group 3: Experimental animals were subcutaneously introduced of cypermethrin at a dose level of 10 $\mathrm{mg} / \mathrm{kg}$ body weight for a period of 7 days, and 14 days.

\subsection{Preparation of histological slide:}

After completion of treatment period, the animals were anesthetized using chloroform and sacrificed by cervical dislocation. Liver and kidney was collected carefully from the mice using standard procedure. Collected organs were washed thoroughly with $0.9 \%$ normal saline to remove any race of blood. Fat tissues adhered to the organs were also removed carefully and afterwards organs were sliced into small tissue pieces using a surgical scalpel for allowing easy penetration of the chemicals inside the tissue. The dissected tissue was treated with Bouin's fluid (fixative) for -16-18 hour and subsequently washed under running tap water for one hour until complete removal of most of the Bouin's fluid from the tissues. Followed by washing, dehydration of the tissues was conducted by immersing the tissue in a series of gradually increasing concentrations of alcohol $(50 \%, 70 \%$, $80 \%, 95 \%$ and absolute alcohol) and embedded into paraffin wax for making blocks. The block was to be trimmed by removing of wax from the surface of block to expose the tissue. Sectioning of the tissue was performed by using a microtome (The microtome machine was sold from Tokyo, Japan by the trade name of SHIBUYA produced by optical. Co LTD). The microtome was pre-set to cut the tissue as thicknesses around 6 $\mu \mathrm{m}$. Blocks Small ribbons of tissue sections were placed on microscopic slide with help of warm distil water containing few drops of Mayer's albumen and deparaffinized with xylene solution. Haematoxylene and eosin yellow solution was used to stain the tissue for preparing permanent slide. Histopathological changes were 
observed under 20x of a light microscope (The microscope was purchased from Italy by the trade name optika) and snaps were taken.

\subsection{Effect of cypermethrin on mice liver}

\section{Results}

Light microscopic examination of liver of control mice demonstrated regular and compact architecture with well-organized hepaticcell and central vain (Fig. 1). Whereas, the section of cypermethrin treated mice showed different histopathological alteration. The slides from treatment group1 showed moderate enlargement of sinusoids, vacuole formations in hepatocytes, congestion in the central vain (this results in dilatation of central veins and pooling of blood in the sinusoids towards the center of the liver lobule) and mild hemorrhage in hepatic tissues (fig 2). Moreover, enlargement of the sinusoids degeneration of hepatic cord, congestion in the central vain and hemorrhage were noted in liver of mice of treatment group 2 (fig 3). The liver section of treatment group 3 indicated granular degranulation of hepatocytes, dilation of the blood vassal, severe congestion of blood vessels and hemorrhage in hepatic tissue (fig 4).

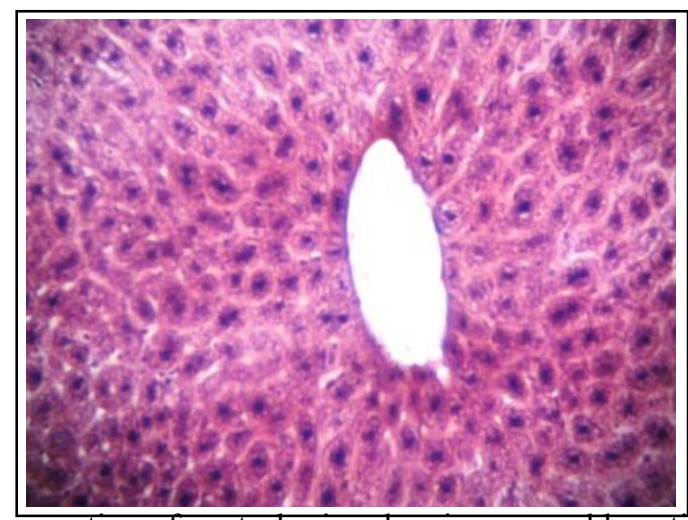

Figure 1: Liver section of control mice showing normal hepatic organization

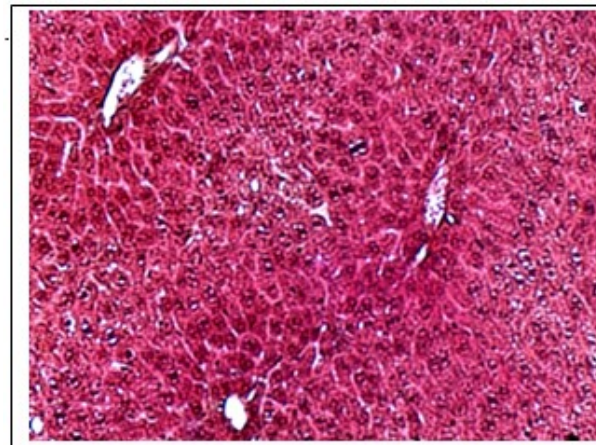

7 days

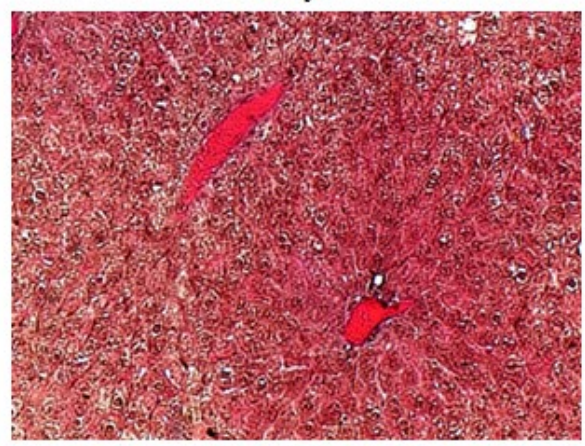

21 days

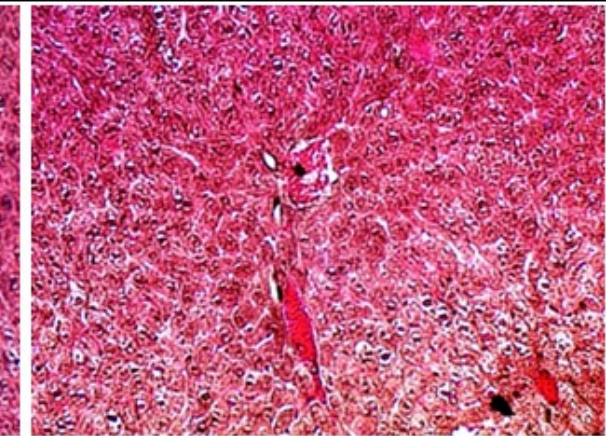

14 days

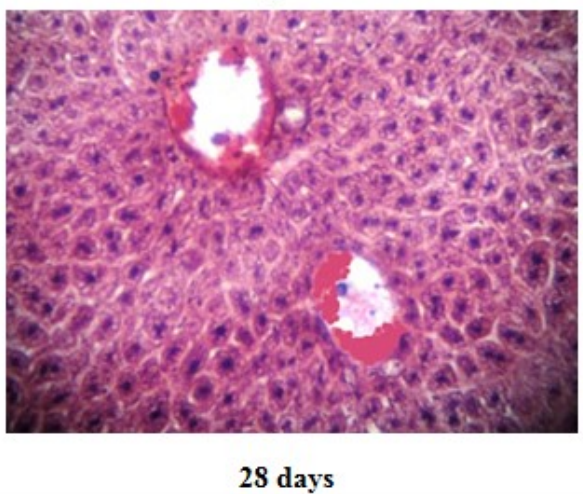

Figure 2: Liver sections of treatment group1 (5 mg/kg body weight). 7 days treatment showed moderate enlargement of sinusoid. Mild hemorrhages were observed in the treatment period of 14 days. 21 days introduction indicated hemorrhage in hepatic tissue. Congestion in the central vain was also noticed in the time period of 28 days. 


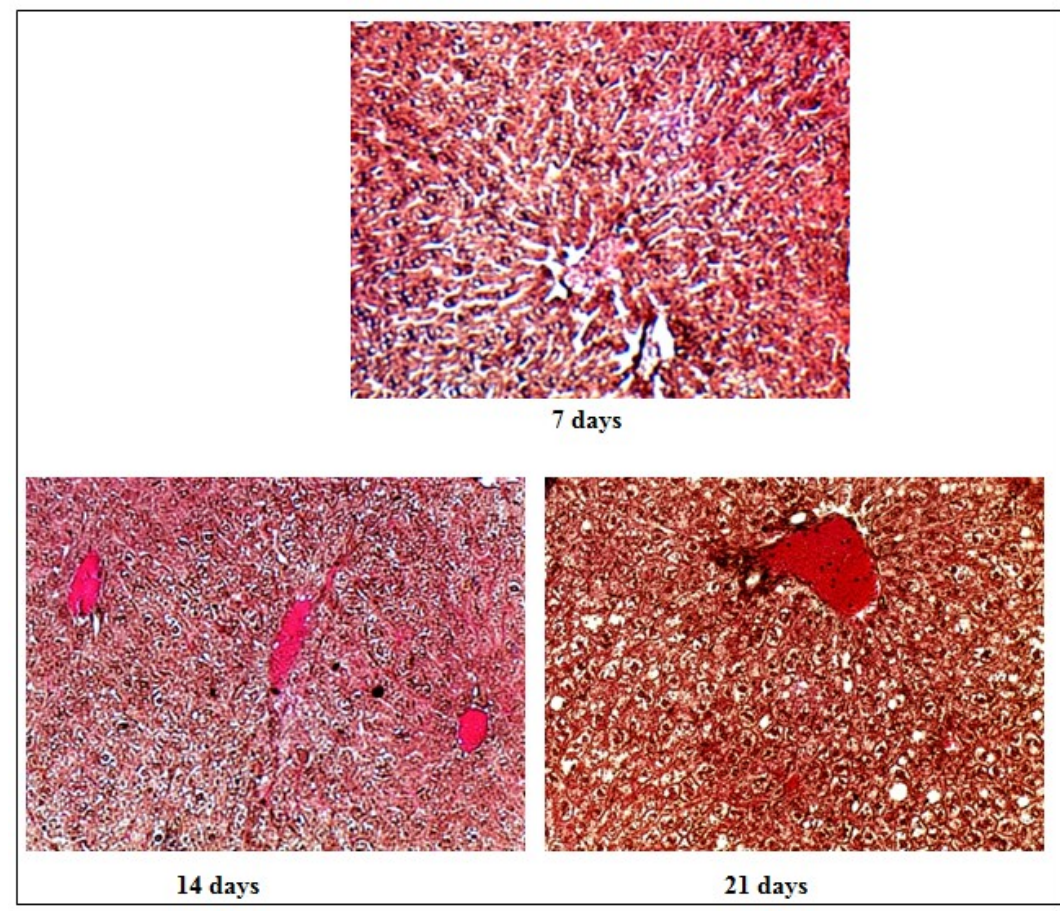

Figure 3: Liver sections of treatment group $2(7.5 \mathrm{mg} / \mathrm{kg}$ body weight $) .7$ days treatment showed enlargement in the sinusoidal space. Hemorrhages were observed in the treatment of 14 days. 21 days administration indicated congestion in the central vain.
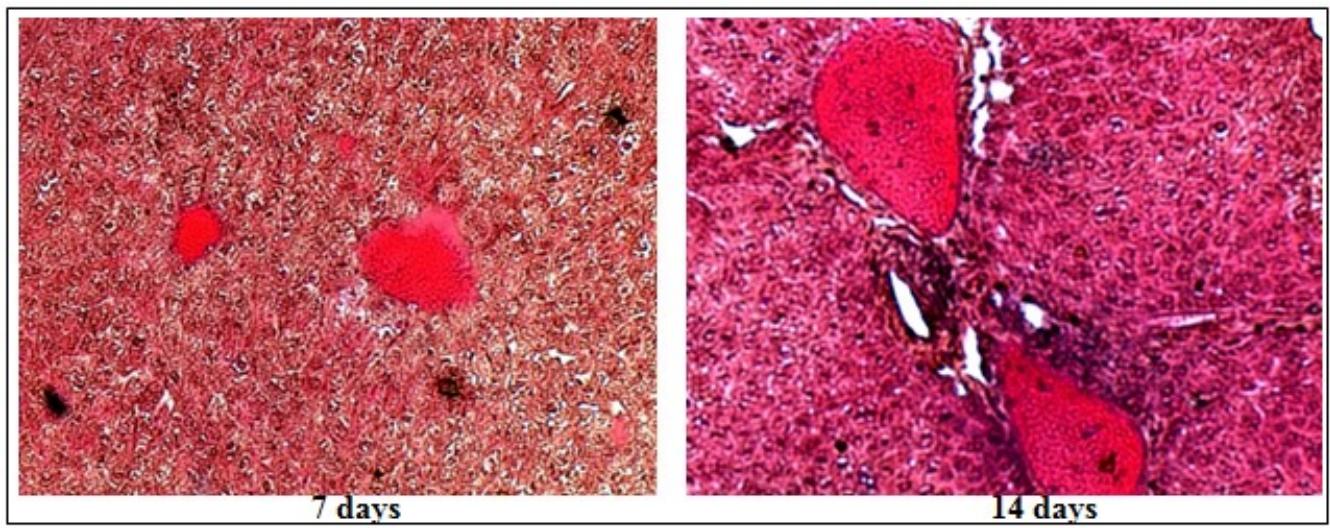

Figure 4: Liver sections of treatment group $3(10 \mathrm{mg} / \mathrm{kg}$ body weight). 7 days treatment demonstrated deletion of the blood vassal and severe congestion in the central vain were observed in the treatment period of 14 days.

\subsection{Effect of cypermethrin on mice kidney:}

Histipathological study on the kidney of control mice showed regular structure with capillaries, tubules, glomerulus, and Bowman's capsule (fig 5). On the other hand, the areas of renal cortex containing renal corpuscles and associated tubules expressed more pronounced changes in treated animals compared with control. In case of treatment group 1 indicated inflammation in the renal tubules, rising renal spaces, shrinkage of glomeruli, eroded Bowman's capsule and marked congestion of renal glomerulus along with hemorrhage (fig 6). Moreover, engorged with blood and hemorrhage in medullary areas, shrinkage of glomeruli and dilated and congested glomeruli along with blood vessels were noted in kidney of mice of treatment group 2 (fig 7). The kidney section of treatment group 3 demonstrated severe congestion, dilated blood vessels, inflammatory leucocyte infiltration and degeneration of their normal shape and structure (fig 8). 


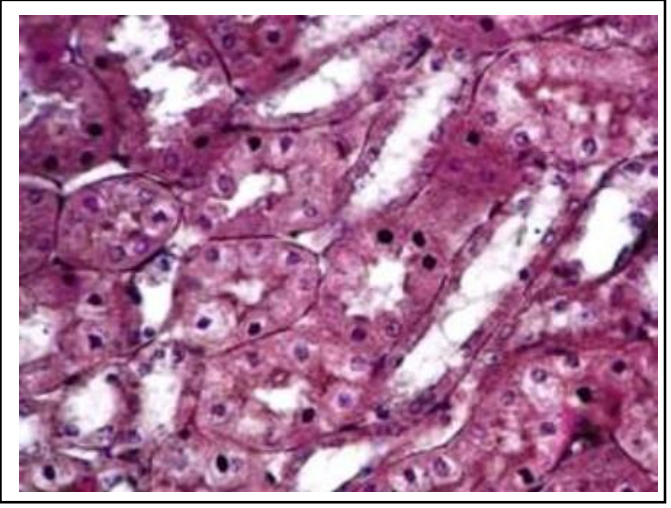

Figure 5: Kidney section of control rat showing normal renal architecture.

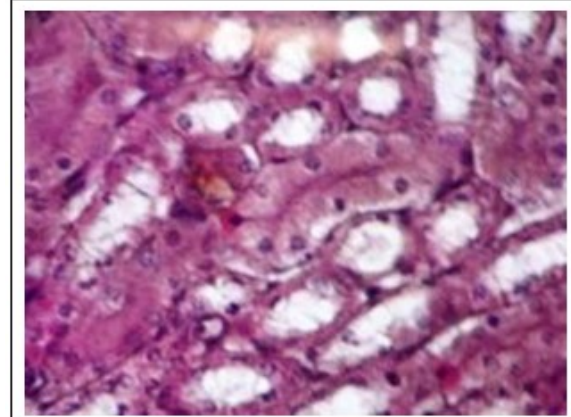

7 days

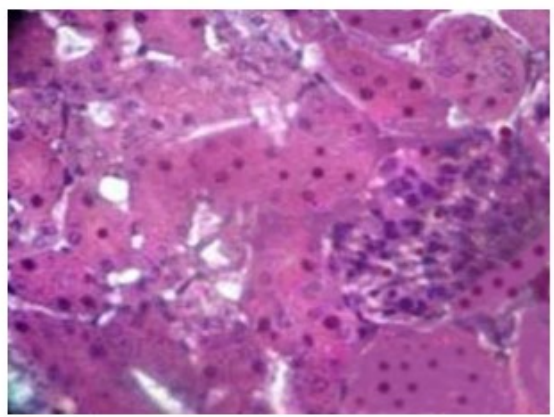

21 days

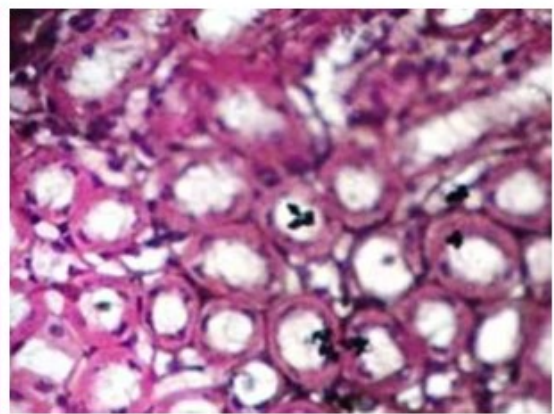

14 days

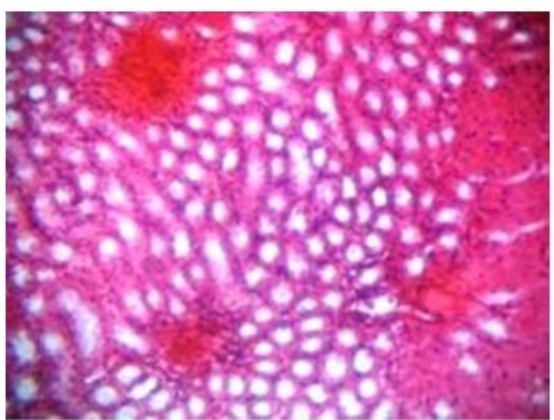

28 days

Figure 6: Kidney sections of treatment group $1(5 \mathrm{mg} / \mathrm{kg}$ body). 7 days treatment showed inflammation in the renal tubules. Rising renal spaces were noted in the administration period of 14 days.21 days introduction showed shrinkage and ruptured in the glomeruli. Congestion of renal glomerulus along with hemorrhage was observed in treatment period of 28 days. 


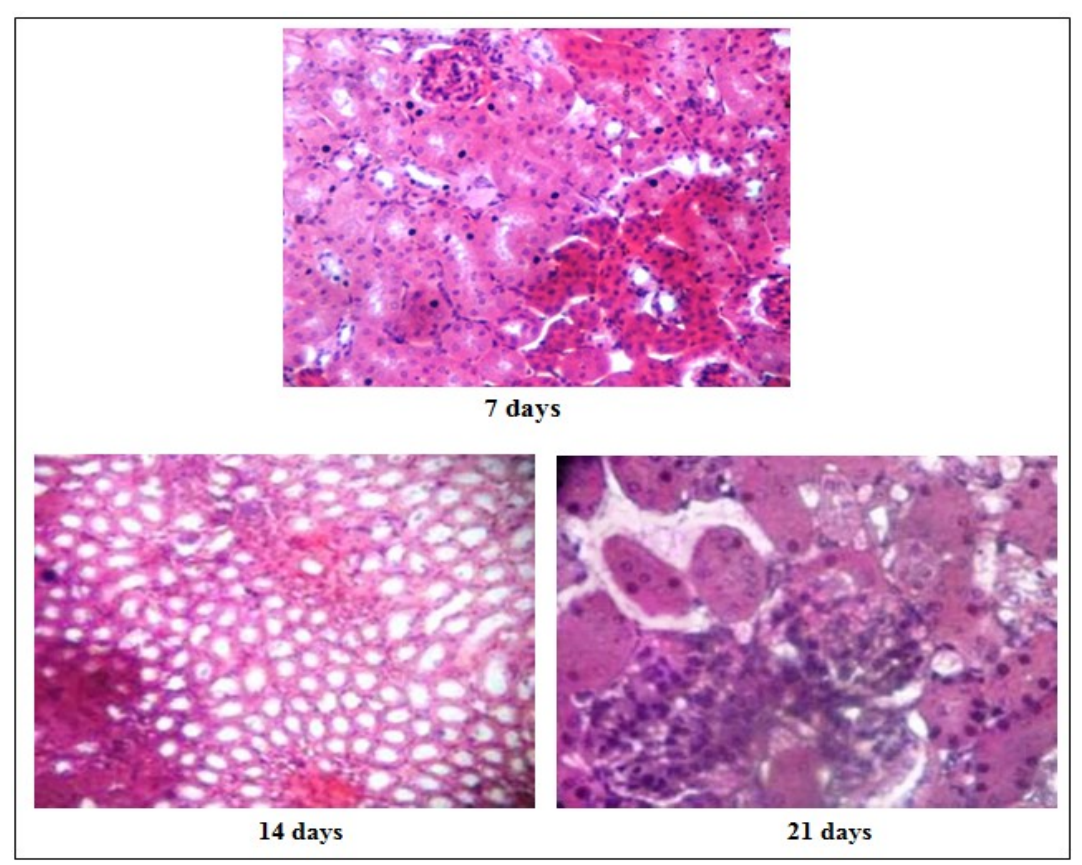

Figure 7: Kidney sections of treatment group $2(7.5 \mathrm{mg} / \mathrm{kg}$ body $) .7$ days treatment showed hemorrhage in medullary areas. Deleted and congested blood vessels along glomerulus were noted in kidney of mice of treatment period of 14 days. 21 days introduction showed shrinkage and ruptured in the glomeruli.

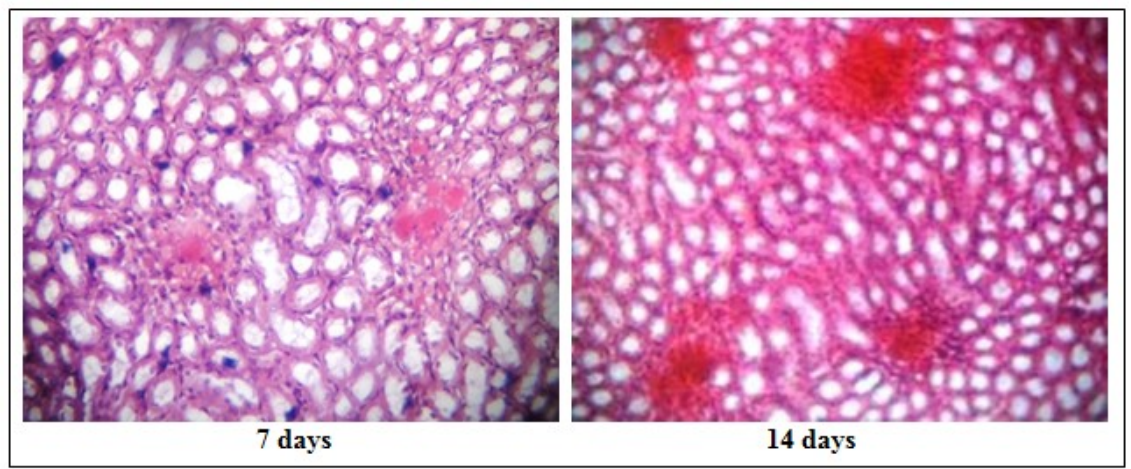

Figure 8: Kidney sections of treatment group3 $(10 \mathrm{mg} / \mathrm{kg}$ body). 7 days treatment showed congestion and hemorrhage in the vain along glomerulus. Severe congested in the glomerulus and deletion of the blood vessels was noted in kidney of mice of treatment period of 14 days.

\section{Discussion}

Sufficient study by diverse workers has already been done on different animal (mice, rats, bird, fish and hamsters etc) about the injurious effect of this culprit chemical through inhalation, dermal and also oral administration and results indicated irritation of the eyes, nose, and skin, abnormal facial sensations, dizziness, headache, nausea, anorexia, fatigue and vomiting [17, 18] .Nevertheless, the data of histological study on the effects of cypermethrin on liver and kidney tissue through subcutaneous administration till was not enough available. In the current histological observation from liver tissue of treated animal showed an enlargement of sinusoids, vacuole formations in hepatocytes, leucocytic infiltrations, and congestion of blood vessels with hemorrhage. On the other hand, the sections from kidney tissue of treated group demonstrated shrinkage of glomeruli, necrosis of renal tubules, congested and dilated blood vessel, eroded Bowman's capsule and marked congestion of renal tubule, glomerulus along with hemorrhage. The results from the present experiment are in agreement with the findings studied by Grewal KK et al (2010) which indicated cypermethrin intoxication resulting deleterious impact on the structure of the liver tissues with necrosis of hepatic cells with pyknotic nuclei, disorganization of hepatic laminae, dilation of sinusoids in hepatic structure and shrinkage of glomeruli, necrosis of renal tubules, hemorrhage and sloughing off renal epithelial cell in the convoluted tubules in kidney tissues [19]. Here, rout of exposure (oral administration) and dose level (higher dose) is different from the present study but showing approximately similar result. The current observation clearly indicated that lower 
dose through subcutaneous administration is enough to cause similar injurious effect with that of oral introduction with higher dose. Jaya Raj et al (2013) reported thatmice exposured orally with the combination of cypermethrin and endosulfan showed medullary congestion in their kidney [20]. According to Ayub-Shah et al (1996) cypermethrin with lower dose resulting mild disorganization of hepatic laminae and higher dose produced necrosis of hepatic cells, with pyknotic nuclei and dilatation of sinusoids with highly disrupted hepatic laminae ${ }^{21}$. In addition, the findings from the current histological observation are in accord with diverse earlier studies which indicated that the introduction to cypermethrin and other pesticides led to provoke intensive physiological, biochemical, histological turbulence in different experimental animals as rat [17], mice [21], rabbit [22], cat [23], broiler chicks [24] and fish [25]. The similar results are reported for malathion, endosulphon and other pesticides indicating exposure of these pesticide leading to encourage histological disturbances in experimental animals [26, 27 and 28]. However, the present study clearly demonstrated that lower dose with higher duration time of treatment causes moderate hepatic and renal damage than those of higher sustainable dose with lower period of treatment.The study showed that nature and intensity of histological alteration resulted by injection of cypermethrin are dose and time dependent. Further examination is needed to carry out for the development of novel therapeutic agent which totally detoxifies the ingredient this toxic substance and finding out probable pesticide which is safe to use. Finally, the present study obviously showed that both the treatment period and cypermethrin dose used here through subcutaneous introduction is enough to cause injurious effect on mice.

\section{Conclusion}

Cypermethrin has injurious effect on public health especially on liver and kidney tissues but intensity of degree damage depend on exposure time dose level. As a result strict law need to be formulated to prevent such oblivious use of cypermethrin during applying in the agricultural sector and it should to be reflected in our health policy. In addition to the novel regulation, the pesticide Incident Monitoring System (PIMS) of Bangladesh have to be more watchful for appropriate implementation of the regulation. The worker should search out novel biological method for combating with insect and pest.

\section{Acknowledgements}

I would like to acknowledge ministry of science and technology of Bangladesh for financial support.

\section{Reference}

[1]. World Health Organization. Environmental Health Criteria. Cypermethrin, Geneva: United Nations Environmental Programme, the International LabourOrganization, and the World Health Organization. 82, 1989

[2]. Tao T Y, Wei L Z, Yang Y, Tao Z \& Zhwo Y. (2008). Affects of alpha and theta cypermethrin insecticide on transient outward potassium current in rat hippocampal CA3 neurons. Pesticide Biochem Physiol, 90:1-7.

[3]. Bouwman H, Sereda B \& Meinhardt H M. (2006). Simultaneous presence of DDT and pyrethroid residues in human breast milk from a malaria endemic area in South Africa. Environ Pollut. 144: 902-917.

[4]. Meister, R.T. (ed). Farm Chemicals Handbook '92, (Meister Publishing Company) Willoughby, 1992.

[5]. Pascual J A \& Peris S J. (1992). Effects of forest spraying with two application rates of cypermethrin on food supply and on breeding success of the blue tit (Paruscaeruleus). Environ. Toxicol. Chem, 11:1271-1280.

[6]. Ray DE, Pyrethroid insecticides: mechanisms of toxicity, systemic poisoning syndromes, paresthesia, and therapy, In Handbook of Pesticide Toxicology,(Ed. Krieger R, Academic Press, USA) 2001, 1289-1303.

[7]. Righi D \& Palermo-Neto J. (2003). Behavioral effects of type II pyrethroidcyhalothrin in rats, Toxicol.Appl.Pharmacol. 191:167176.

[8]. Vijverberg HP \& van den Bercken J. (1990). Neurotoxicological effects and mode of action of pyrethroid insecticides, Crit Rev Toxicol, 21:105-26.

[9]. Ramadan A A, Bakry M N, Salam M A, Marei, Eldefrawi A T \& Eldefrawi M E.(1988). Action of pyrethroidson GABAAreceptor function, Pest. Biochem.Physiol, 32:97-105.

[10]. Miyamoto J, Kaneko H, Tsuji R \& Okuno Y (1995) Pyrethroids, nerve poisons: how their risks to human health should be assessed, Toxicollett. 82: 933-940.

[11]. Rao, G V \& Rao K S J. (1993). Inhibition of monoamine oxidase-A of rat brain by pyrethroids- an in vitro kinetic study, Molec. Cell. Biochem 124: 107-114.

[12]. Tample W A. \& N.A. Smith, Cypermethrin. Environmental potential agency. 1996.

[13]. Amer S M, Ibra A A \& himel-Sherbeny KM. (1993). Induction of chromosomal aberrations and sister chromatid exchange in vivo and in vitro by the insecticide cypermethrin, J. Appl. Tox, 13: 341.

[14]. Singh A K, Tiwari M N, Upadhyay G, Patel D K, Singh D, Prakash O \& Singh M P.(2012). Long term exposure to cypermethrin induces nigrostriatal dopaminergic neurodegeneration in adult rats: Postnatal exposure enhances the susceptibility during adulthood, Neurobiology of Aging, 33: 404-415.

[15]. Kumari V, Kaur B \& Sandhu H S. (2002). Experimental cypermethrin toxicity in buffalo calves. Indian J Anim Sci, 72: 658-60.

[16]. Hussain S, Khan M Z, Khan A, Javed I \& Asi M R. (2009). Toxico-pathological effects in rats induced by concurrent exposure to aflatoxin and cypermethrin, Toxicon, 53: 33-41.

[17]. Nagarjuna A \& Doss P J. (2009). Acute oral Toxicity and Histopathological studies of Cypermethrin in rats, Indian J Anim Res, 43: 235-240.

[18]. Righi D A \& Palmermo-Neto J. (2003). Behavioral effects of type II pyrethroidcyhalothrin in rats, ToxicolApplPharmacol, 191: 76167. 
[19]. Grewal K K, Sandhu G S, RanjitKaur, Brar R S \& Sandhu H S. (2010). Toxic Impacts of Cypermethrin on Behavior and Histology of Certain Tissues of Albino Rats, Toxicol Int. 17: 94-98.

[20]. Jaya Raj, Mohineesh, Ruma Ray, T. D. Dogra \& AnupumaRaina. (2013). Acute Oral Toxicity and Histopathological Study of Combination of Endosulfan and Cypermethrin in Wistar Rats, Toxicol Int,; 20: 61-67.

[21]. Shah M A, Gupta P K \& Tandon H K. (1996). Effect of permethrin,: A synthetic pyrethroid on pentobarbitone induced sleeping time and hepatic microsomal constituents in mice, Ind J Toxicol, 3: 19-23.

[22]. Wlodarczk B, Minta M \& Jurzkiewicz T. (1995). Influence of cypermethrcin on pregnancy and fetal development in rabbits, MedycynaWeterynaryjna, 51: 31-33.

[23]. Husain R, Malaviya M, Seth P K \& Husain R. (1994). Effects of deltamethrin on regional brain polyamines and behavior in youg cats, PharmacolToxicol, 74: 211-215.

[24]. Majumder S, Chakraborty A K, Mandal T K, Bhattacharya A \& Basak D K. (1994). Subacute toxicity of fenvalerate in broiler chicks: Concentration, cytotoxicity and biochemical profiles, Indian J Exp Biol. 32:752-756.

[25]. Velmurugan B, Mathews T \& Cengiz E I. (2009). Histopathological effects of cypermethrin on gill, liver and kidney of fresh water fish Clariasgariepinus and recovery after exposure, Environ Techno,.30:1453-1460.

[26]. Ahmed M \& Nasr H M. (2009). Dimethoate-induced changes in biochemical parameters of experimental rat serum and its neutralization by black seed ( Nigella sativa L.) oil, Slovak J Anim Sci, 42: 87-94.

[27]. Yousef M I, Demerdash F M, Kamel K I \& Al-Salhen K S.(2003). Changes in some hematological and biochemical indices of rabbits induced by isoflavones and cypermethrin, Toxicology, 189: 223-4.

[28]. Adeniran O Y, Fafunso M A, Adeyemi O, Lawal A O, Ologundudu A \& Omonkhua A A .(2006). Biochemical effects of pesticides on serum and urinological system of rats, J Applied Sci,6: 668-672. 